\title{
Publishing After the Apocalypse
}

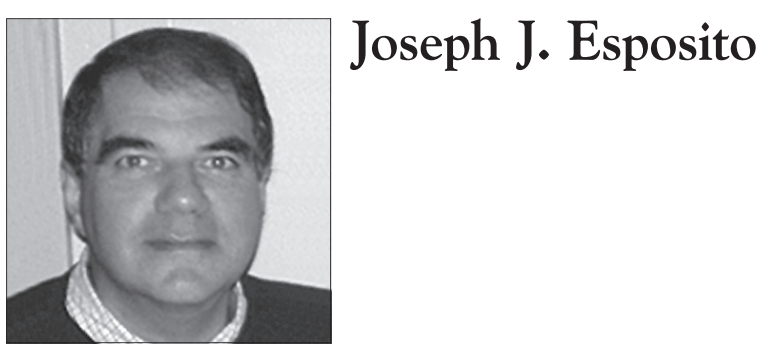

Joseph J. Esposito has served as an executive at Simon $\&$ Schuster and Random House, was President of Merriam-Webster, and CEO of Encyclopaedia Britannica. He has also been CEO of Internet communications company Tribal Voice and SRI Consulting, both of which he led to successful exits. Among Esposito's clients have been Microsoft and Hewlett-Packard, various publishers, and a number of not-for-profit organizations like JSTOR, the University of California Press, and the American Nationals Standards Institute.

Esposito is President of Portable CEO, an independent consultancy focusing on strategy for the publishing and software industries, with a special emphasis on digital media.

E-mail: espositoj@gmail.com
One of the abiding myths of publishing and scholarly communications is that we are living in a world that is hurtling toward the future. I use the term "myth" not to mean something that is not true but rather as a controlling metaphor for the way we think about things. This thought was prompted by my recent participation in a panel at the 30th Annual Charleston Conference (amusingly identified in Roman numerals, the "XXX Annual Charleston Conference," to the discomfort of the many librarians in attendance), from which this essay is derived. The name of this panel captures the myth: I Can Hear the Train a-Coming. Good name, taken from a great song. But some of us are likely to reflect that trains are an old technology and if they are taking us anywhere, it is from one point in the past to another point in the past. We might well begin to wonder to what extent we are blinded by the metaphors we use, the hurtling train among them.

So I have begun to wonder what happens when the train stops. By this I don't mean that the world has come to an end, but rather, if we are indeed hurtling toward the future, what is that future state? This is a different matter from identifying the trend lines that are pointing to the future: the trend lines take you up to a future point, but they don't tell you what you will experience on the other side. Will it be simply an ongoing series of disruptive events, such as the publishing community is experiencing today, or will it reach a point of relative stability? Do all the disruptive forces at work today, from ebooks to cloud computing, all come together at last, after they have had a chance to bang our heads together for awhile, and come to define a less disruptive future state, where instead of watching for fast-moving trains (and giving prognosticators like myself a means of earning a living), we get off the train and go about our business? And, yes, this begs the question, when the train stops, precisely what will be that business? 
What happens after the Apocalypse?

Instead of trains, I would like to evoke a different metaphor, one that is associated with evolutionary biology and the late Stephen Jay Gould: punctuated equilibrium. Gould argued that the history of life on earth consists of long periods of relative stability, but then suddenly there would be an enormous disruptive event. During the disruption, many species die out, and many new species are formed. But then, when the dust settles (which may not be a metaphor if you subscribe to the view that some mass extinctions were caused by a meteor hitting the earth and forcing a huge amount of debris into the atmosphere, blocking out the sun and destroying vegetation), a period of relative tranquility begins. "Relative" is, of course, a relative term: in our own era of relative stability, we still witness earthquakes and tornadoes and have begun to wonder about the fate of the polar ice cap. A period of equilibrium does not mean that there are no conflicts or challenges but that the basic design of the environment remains largely unchanged.

One of the axioms of publishing today is that big changes are being wrought by information technology. It would be hard to argue with this proposition. But it is useful to reflect that even IT sometimes stops punctuating and enters a period of equilibrium. We are still living in such an era now, the PC Age, which was largely created and entirely dominated by one company, Microsoft. Although it is fashionable - and true - to say that the PC Age is coming to an end, that cloud computing is taking over, that Microsoft has forgotten how to innovate, and that the iPhone is the harbinger of a new world of intelligent, mobile devices, the fact is that when you look at the IT behavior of most people, you find that they continue to use PCs that run Microsoft Windows, create documents in $\mathrm{Mi}$ crosoft Office, and manage a huge proportion of email, perhaps most, through a Microsoft Exchange server linked to Outlook. We have been experiencing this period of relative calm in computing for almost 20 years now. The fact is that IT disrupts, but then creates its own more stable environment, from which it harvests staggering profits.

This does not mean that PCs are not disruptive; it just means that PCs are not disruptive to PCs.
The question is whether you live outside the PC environment, as companies like IBM, Sun, and many others I could name did, or inside it, happily beavering away on the estate rented to you by Bill Gates. The disruptive PC became the new normal. Now, of course, the combination of cloud computing and intelligent handheld devices is seeking to disrupt the happy valley of the PC. Once again the question is, are you inside or outside that particular environment? If you are among the very few that have already migrated to the post-PC ecosystem, the disruptions of the legacy environment are of no concern, and if you are among the fortunate companies that serve the new environment - companies like Apple, Google, and Facebook - the opportunity for financial gain is staggering in its proportions.

Let's take an example that is closer to home: scholarly journals. We all know the story: the monopolistic trading practices of the largest STM publishers coupled with the clever use of technology to sell digital subscriptions have driven prices up, jeopardizing libraries and potentially endangering the quality of research. Although I would probably shy away from any variant of the word "monopoly," it does seem to me that the standard narrative is true, if incomplete. What is stated less often is how stable that publishing environment has been for decades now. By analogy, Elsevier and Springer have been to research publishing what Microsoft and Intel have been to PCs. They disrupted the previous paradigm (you could say that Robert Maxwell was the Bill Gates of academic publishing), established a period of relative equilibrium, and profited handsomely from it. They were disruptive, but, importantly, they did not disrupt themselves.

How resilient has this paradigm been? I think the answer lies in this: despite the many worries of librarians, the growth of the Open Access movement, and the economic pressure on institutions everywhere, five years from now the $\$ 7$-billion global journals publishing business is not likely to be much smaller than it is today. Of course, it may not be any larger either, but like Microsoft Windows and Outlook it has a lot of life in it yet. But what happens when the train pulls into the station? Now that the subscription-based paradigm is showing its 
wear, what does the world look like on the far side of the current disruptions?

\section{Every disruption is followed by a period of relative calm, which in turn is followed by another disruption, another calm: punctuated equilibrium.}

One vision of the future is for continuing disruption. This is, perhaps, a misappropriation of Trotsky's and Mao's notion of continuous revolution - and sometimes indeed it seems that the most strident voices of change in scholarly publishing come from latter-day activists operating in the style of the 1960s. Advocates of this point of view note correctly that disruption is everywhere, that sturdy oaks continue to fall to the chainsaw, that information technology has barely got started yet. This perspective is wrong on two counts. First, it is belied by the evidence in other areas, as in the example of the relative stability of the Microsoft PC era. Every disruption is followed by a period of relative calm, which in turn is followed by another disruption, another calm: punctuated equilibrium. But the more important limitation of the "infinite disruption" outlook is that it provides no way to finance an endless series of disruptions. It is axiomatic that any new information service must sooner or later identify a means to pay for itself, even if that payment takes the form of committed funds from government or philanthropy. At some point the disruptor must become the harvester; at some point all the changes in the world of publishing and scholarly communications must settle down long enough for someone to profit from them. If that period of stability does not arise, there is no way to attain the capital to fund the next disruption. Like the virus that feeds on its host, the disruptor always requires that a heartier host come along.

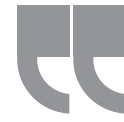

\section{....at some point all the changes in the world of publishing and scholarly communications must settle down long enough for someone to profit from them.}

If what we are looking for is a period of stability from which someone can profit, what do the conspicuous trend lines suggest to us? The trends that have captured my attention (there are other trends, of course, but the ones I am citing here simply feel to me to be the ones that will converge at the station stop) concern issues of funding, the implications of the global Internet, and the astounding capability to capture data on actual usage of published materials, which in turn leads to new forms of direct marketing. While I am choosing my examples primarily from scholarly publishing, most of the points raised here apply to other publishing segments as well.

Let's summarize these trends:

1. The funding issue. It's useful to remind ourselves that perhaps $85 \%$ of all expenditures for academic journals comes from university libraries. (The share for books is much lower than that; for the university press segment, perhaps 25\%.) Libraries have been under budgetary pressure for some time now, and the worldwide financial crisis triggered by the housing bubble has intensified that pressure. Libraries are cutting back because they have to.

\section{Library bypass. This is an inevitable out-} growth of the funding crisis in libraries. Publishers that now see that libraries cannot be counted on for continuing growth are seeking new markets for their products (in addition to fighting aggressively for the shrinking pie of library money). This takes the form of seeking enlarged business in corporate and government accounts and probing sales opportunities in developing markets. Another form of library 
bypass is to seek to market products to other budgetary centers within the academy, typically directly to research personnel.

3. Supply-side publishing. This will be discussed in greater detail in a moment, but for now let's simply call it publishing outside the traditional framework of submitting manuscripts to established publishers, which then review it editorially prior to publication. Open access publishing is one, but only one, form of supplyside publishing. Supply-side publishing derives from two wellsprings: the funding issue, which makes it harder for authors to find traditional publishers to take on their work, and the inherent characteristics of digital technology, which lower the barrier to make content available, at least on the Web. Add to this the need and desire for research personnel to communicate their findings to others in their field and you have a burgeoning trend.

\section{Direct marketing. Partly as an aspect of a} library bypass strategy and partly because of capabilities of digital media, more and more publishers are now selling their products directly to individuals, a tactic known in the trade as "D2C" - direct to consumer. This is most evident in books (almost all publishers now take orders directly on their Web sites), but it is becoming more widespread for every category of publication. Digital technology makes it possible to collect user data, analyze it carefully, and prepare persuasive direct-marketing campaigns. If the Internet and the economy were entirely friction-free, D2C marketing would dominate. But the economy is anything but friction-free (regulatory issues, the clout of established intermediaries such as Amazon, etc.). Thus direct marketing is typically but one of many ways publishers seek to reach their ultimate customers.

5. Social networking. I think it's fair to say that the role of social networking for scholarly communications is still out with the jury. Every week we hear about a "Facebook for scientists," but the fact is that for the most part, many of the features we now know as Web 2.0 have not yet anchored themselves in the research community. It appears that social networking is likely to evolve as a principal form of discovery for research materials. If this is true, this could play a role in influencing such things as impact factors and it could also serve to undermine the value of some publishers' brands. It is less clear that social networking will play a large role in the creation of scholarly content itself, as usergenerated content pulls in the opposite direction of the authoritative work of the academic community.

\section{We thought that with the Web, systems would become increasingly open, but in the world of publishing, things are moving in the opposite direction.}

6. The resurgence of proprietary systems. We thought that with the Web, systems would become increasingly open, but in the world of publishing, things are moving in the opposite direction. Amazon, Barnes \& Noble, and Apple all have proprietary systems for ebooks, a situation that would have been hard to imagine even a few years ago. The open Web is becoming less open. For example, although it is axiomatic that Google has replaced many search mechanisms, some services (Facebook being the biggest of them) don't permit Google to index them. Digital media is becoming balkanized, and the reason for that is that balkanization in many ways lends itself to monetization.

Let's spend a minute on supply-side publishing and distinguish it from traditional publishing, which we can call "demand-side" publishing.

In demand-side publishing, the presumption is that there is a market for a work. A market means 
that money changes hands. Users do not in themselves create a market unless they or their proxy pay for services. A demand-side publisher naturally seeks to gain control of those works that are most likely to sell and will focus in particular on works that sell particularly well. This means that some works will not find a publisher, as a publisher may not believe that a particular work will find a market of willing customers. Demand-side publishing thus restricts the amount of information that becomes available through its insistence that end-users support the publications through purchases.

With supply-side publishing the game is reversed. Typically a supply-side service (the Public Library of Science, BioMed Central, and Hindawi come to mind, but there are many, many others) looks upstream, to the author, for payment. Thus the author, not the reader, is the customer, so publications may appear without regard to whether or not there is a likely readership. Supply-side publishing is still market-based, but the market is among authors, not readers.

\section{Supply-side publishing is still market-based, but the market is among authors, not readers.}

Many critics of supply-side publishing attack it on the basis that it can approach vanity publishing. I think this is just plain wrong. Some supplyside services have rigorous editorial controls. But even if such controls were not up to the standards of the most selective traditional journals, some research materials have merit even if they cannot find a market among readers large enough to support the publication. For that matter, publications with no readers whatsoever have value in that they help train the professionals who write them and they serve as "just-in-case" documents for when a need may arise. Surely I am not the only individual whose personal library includes volumes that I have never opened, but that are part of my intellectual framework, as I know that I can easily retrieve information from them. And I do believe I sleep better knowing that the two-volume Modern Library Edition of Gibbon's Decline and Fall stands guard on the bedside table, unopened. When we talk about "proper" publications, meaning those published in the traditional manner, what we really mean is that our standards take their measure from the requirements of the marketplace.

When the train arrives at the station, the funding crisis is likely to still be with us, but the aim of researchers to continue to see an audience for their works will be undiminished and may in fact continue to grow. Thus the future of supply-side publishing seems assured. Demand-side publishers, of course, will not take this lying down. They will seek new opportunities beyond their traditional base in academic libraries and may even attempt to co-opt some aspects of supply-side publishing. We are already seeing this in what Phil Davis calls "cascading peer review": a traditional journal continues to solicit material for its demand-side flagship, but then creates an alternative service for articles that are deemed not to be "good enough" (meaning they fall outside the requirements of demand-side publishing); this second service turns the business model on its head and publishes works when an author pays for these services, not when there is an expectation that a willing readership will step up to support the publication.

Publishing after the apocalypse thus consists of two often competing, sometimes collaborating models, both of which are increasingly wrapped within social networks to facilitate discovery. These competing models of supply-side and demand-side publishing are both highly diverse, just as traditional publishing is diverse. Neither sits still; both continue to innovate. But they reach a period of relative stasis, in which the practitioners in either field learn how to generate revenue, whether from readers or from authors.

And there is quite a bit of money to be made. While supply-side publishers continue to add services to attract more paying authors, publishers on the demand side (when they are not busy co-opting supply-side publishers) will be seeking ways around the library funding problem. This will lead them (it is already beginning) to a resurgence of marketing directly to end-users. The Internet lends itself to this, as it enables the capture of every keystroke 
and provides a low-cost way to test new offerings. Demand-side publishers are likely to evolve by, first, adopting some of the traditional strategies of direct marketers (and for some of the same reasons) and, second, by exploring the implications of digital publishing, with its absence of variable costs. This will lead them to what I call "attention publishing," where the critical issue is not the content that is sold but the ability to monopolize the time a prospective reader has. Attention is the scarce commodity, and all marketers seek to support something scarce, the better to earn a return on capital.

Let's back up a minute to explain this. Let's say a traditional publisher, with a stable of successful journals that are largely sold to the library market, reacts to the market environment by attempting to set up a direct-marketing business. The publisher quickly sees that the big cost in direct marketing is customer acquisition, a cost that was not nearly so prominent with library sales, as libraries aggregate a great number of users from a single sales call. The publisher thus seeks to lower the cost of customer acquisition by selling each customer more than one item, which naturally leads to selling subscriptions instead of single articles or issues of journals or even of individual copies of books. Customers thus become subscribers to information services, and the services themselves will adapt to make them increasingly palatable to this market.

At this point the demand-side publisher says, what is the next step? I am now selling subscriptions directly to end-users, but how do I grow my business? This publisher will be familiar with the Big Deals offered to libraries and seek to borrow that marketing idea for the direct-to-consumer market. Just as the Big Deal tends to monopolize libraries' attention by providing more journals than would be purchased on a solitary basis, the cousin of the Big Deal for consumers will provide a great deal of information directly to end-users, thereby seeking to control more and more of an individual's reading time.

Here is a concrete example. Let's think about Penguin Classics, one of the most distinguished series for the intelligent general reader. There are 1,082 titles in Penguin Classics, more than most readers, however serious, will read in a lifetime. I am a reader of Penguin Classics myself. I read perhaps two books from the series every year, at a cost of approximately $\$ 30$. On that $\$ 30$ Penguin makes a gross profit of perhaps $\$ 7.50$, perhaps a bit less after royalties are taken into account. I read more than two books a year, of course, but Penguin has to compete with many other claims on my attention, whether that comes from other publishers, film, music, or any other way I might spend my discretionary time.

If Penguin is going to become an "attention marketer," it will quickly realize that the biggest opportunity is to convert the $\$ 7.50$ it earns from me into a bigger number. Let's propose that Penguin now makes its entire Classics series available to individuals in electronic form for a subscription of $\$ 50$ a year. The first reaction by a publisher to a suggestion like this is, we can't give all those books away for that price! But of course you are only "giving away" what a reader has the time to consume.

I would sign up for such a subscription from Penguin in a minute. As a subscriber I would quickly see that every book I read is "free," that is, it has no marginal cost to me beyond the fixed cost of the subscription. This will provide an incentive for me to read more Penguin Classics - Penguin is now beginning to monopolize my attention. If any of this sounds bizarre, reflect for a moment on how your subscriptions to cable television and Netflix work. Since I became a Netflix subscriber, the number of movies I watch has skyrocketed. Netflix offers me far more movies than I could ever watch, and all for one fixed price. As a consequence of my Netflix subscription, I use my television set less and less as a television and increasingly as a display monitor for Netflix.

For Penguin or any other publisher to do this, it will need to hone its direct-marketing skills and it will need to have the technology to deliver the works in digital form, preferably in a way that does not encourage piracy. It is thus likely that the proprietary systems of Amazon, Apple, etc. will soon be competing with service providers that create subscription-based applications for publishers, just as we now have in the library market for journals, where the likes of HighWire, Atypon, and AIP compete for clients. A new publishing ecosystem will grow up, but it will only arise when the man- 
agement of these organizations can foresee an end to ongoing disruption and can make a good case for investing in these technologies now.

To sum this up, when the train comes into the station, we will experience post-apocalypse publishing, a new period of relative calm in which investments can be made and profits earned. A future of ongoing disruption is unlikely, as it will not permit the creation of capital to fund the next disruption. The publishing landscape will have two broad models: supply-side publishing, which is effectively the heir to the current open access movement; and demand-side publishing, heir to today's traditional publishers, which will increasingly move to new forms of attention marketing. The interaction between these two models will be fascinating to watch, but it seems unlikely to me that the supply-side form will be entirely co-opted by demand-side publishers. The Internet is not finished with us yet. 